\title{
Color Reflection of Security in Urban Community Signage System
}

\author{
A Case of Baibuting Community*
}

\author{
Shu Zhang \\ School of Art \& Design \\ Wuhan University of Science and Technology \\ Wuhan, China 430065
}

\author{
Qianqian Zhao \\ School of Art \& Design \\ Wuhan University of Science and Technology \\ Wuhan, China 430065
}

\begin{abstract}
Urban residential community is a kind of living mode of people, which, in some ways, constitutes a relatively complete social communication network. The signage system in an urban community is an important means and way to convey information in the space, of which community safety is an indispensable aspect of the residential community, and an important content of the orderly development and construction of the community. With the development and integration with art of modern cities, people have higher and higher demands for aesthetic characteristics of the signage system designed in the community. Therefore, it is necessary to carry out personalized innovative design of the signage system in community, and conduct in-depth and detailed research on the concept and method of public space identifier design. Signage system design follows the basic principles of modern design, including scientificity, practicability, applicability and functionality. Firstly, through literature consultation, network data collection, field research and analysis and other relevant methods, this paper analyzes and studies the design of the color signage system and its visual expression in urban communities at home and abroad, and makes corresponding comparison and summary. Secondly, the paper focuses on the related laws, ideas and methods of color signage design in urban communities. Finally, based on the previous theoretical analysis and research, the paper carries out innovative practice in terms of color safety in the signage design by taking the example of Baibuting Community, so as to achieve the purpose of color safety design in the signage design and realize the feasibility and practicability of the scheme from the perspective of the design.
\end{abstract}

Keywords-urban community; signage system; safety; color; Baibuting community

\section{INTRODUCTION}

Approved by UNESCO through assessment, Wuhan city was officially selected as the "City of Design" of 2017 Creative Cities Network, thus becoming the third "City of

*Fund project: This paper is a phased achievement of 2017 provinciallevel teaching research project of Hubei colleges and universities "Research on Practice Teaching Model for Visual Communication Design Major from the Perspective of Community Service" (project number 2017245); and a phased achievement of 2018 humanities \& social sciences research general project of Hubei Provincial Department of Education "Research on Urban Color Culture based on GIS platform - A Case of Central Urban Area of Wuhan City" (project number 18Y029).
Design" of China after Shenzhen, Shanghai and Beijing, and also the first one in inland China. In addition, Wuhan continues to win the title of "National Civilized City". In the same time, the people's government of Wuhan puts forward the general goal by 2049: to make Wuhan a more competitive and sustainable world city. In this context, China's urban residents raise higher requirements on living environment, and the design of signage system should also change with the development to adapt to the trend and innovation of the new era. The signage system can be seen everywhere in modern life, which uses visual symbols to transform information into images and can make people feel an unprecedented visual effect. This pager, through literature consultation, research, information query and research methods and strategies, provides better design innovation of signage system in urban communities, and put forward some design schemes, aiming to provide better visual enjoyment and experience for residents, bring them new feelings and facilitate better development of communities.

\section{A. Purpose and Significance}

Residence community is the epitome of society. With the development of economy, people raise higher and higher requirements for living environment, not only for the residence, but also for the environment of the community. As a result, the spatial layout of buildings and supporting facilities in the community becomes more and more complex. Therefore, in the early stage of community construction, it is necessary to develop an effective signage system to provide guidance and protection for residents and arouse their attentions.

Firstly, the signage system can not only facilitate the residents of the community to find the destination reasonably and quickly, but also help them more conveniently use various facilities in the community. Secondly, signposts with visual impact, the appearance design with interestingness and era characteristics, pavement design, etc. will play a better role in protecting and guiding the children, the elderly and the disabled in this residence area. Thirdly, excellent design of a signage system can provide convenience for people who come to the community for the first time to find their destination more quickly in this unfamiliar place, and also can help them learn about the routes the community. Finally, good signage design is characterized by high functionality, rationality and 
practicality, which can reflect humanization and suitable for different people.

\section{B. Research Idea and Method}

Through comprehensive analysis based on literature and network data collection of and field investigation, the paper conducts comparative study of urban communities and Baibuting Community to grasp the influencing factors and value of color safety in signage design. In addition, after several times of field investigation, the paper, through analysis and summary, lays the groundwork for the follow-up design. By summarizing the research and analysis, taking Baibuting Community for example, the author puts forward practice and innovation of colors in signage design.

This paper, based on information retrieval and induction method, consults relevant literature and data to analyze the existing deficiency; through field investigation, conducts horizontal-vertical investigation and analysis to provide guidance for the research; through practical design and application of research methods, analyzes the relationship between the signage design of Baibuting Community and the population, and innovate its practice on the basis of relevant theories and design methods.

\section{RESIDENCE COMMUNITY AND COLOR DESIGN OF SIGNAGE SYSTEM}

\section{A. Definition of Basic Concepts}

1) Concept of community: Community is an interconnectedlarge group of life formed by a number of social groups or social organizations gathered in a certain field. It is generally believed that a community should include a certain number of people, a certain region, a certain scale of facilities, culture with certain characteristics and organizations of certain types. Community is such a "social life community formed by people living in a certain area".

2) Concept of signage system: Signage system design is an interdisciplinary subject between traditional architectural design and visual communication. Modern urban life raise higher and higher information relationship between people and the environment, ranging from an office building to a region or even a city, which requires scientific and humanbased navigation design.

3) Concept of color in signage system: The color of signage contains three attributes: hue, brightness and purity. Understanding these attributes of color can effectively guide you through arrangement of the colors required by the project. In the humanization design of the signage system, color is an important means to form systematicness and recognizability. On the one hand, it guides the environment; on the other hand, it can trigger various feelings and associations of people.

4) Concept of safety: Safety is, in the process of human production, to control the possible damage to human life, property and environment by the running status of a system under an acceptable level.

\section{B. The Forming Compositions and Elements of Signage Design of Baibuting Community}

The Baibuting Community space signage design is divided into two aspects: signage and guiding. The signage includes, for example, community planar distribution diagrams, bulletin boards, and so on. The planar distribution diagram makes it easy for people to understand where they now are and provides location information. The bulletin board is located on each side of road in the community, which makes people understand the major and minor issues of the community and improves the surrounding information. The guiding includes signposts, building numbers, emergency safety exits, instructions for use of fire hydrant, etc. The combination of colors, graphs and texts can better guide the direction and route.

Taking the Baibuting Community as the main body, this paper focuses on the analysis and design of the signage system to research the importance of color in the signage design. On the basis of this, this paper also makes a preliminary design of the building number, the road pavement, the street lights and the direction signposts in the signage system, and carries out a series of innovative designs on the color, which lay a solid foundation for the future complete set of design.

\section{The COlOR SAFETY OF THE BAIBUting COMMUNity SigNAGE SYSTEM}

\section{A. Baibuting Community}

Baibuting Community remains a demonstration site of national civilized communities, which is the only community that won the first "China Habitat Environment Model Award". The community adheres to the core ideology of "putting people first, taking morality as the soul, civilization as the beauty, and harmony being invaluable", and the scientific outlook of development, thus creating a harmonious community with Chinese characteristics. Baibuting Community has realized the sustainable development of new type of community, as evidenced by better management services, good public orders, beautiful ecological environment, close interpersonal relationships, civilized social customs, and living and working in peace and contentment.

Baibuting Community has won more than 60 national-level awards, including the Advanced National Primary Party Organization, the National March 8 Red Flag Group, the National May 4 Red Flag Chinese Communist Youth League Committee Model, the National Cultural Advanced Community, the National Non-toxic Community, the Advanced National Primary Militia Reserve Unit, and the National Property Management Excellent Residential Community, the National Independent Innovation Award for Building Harmonious Community and so on.

\section{B. Investigation of Baibuting Community Current Situation and Existing Problems}

The quality of the signage system design directly affects the living environment of the residents. Therefore, in addition to the aesthetics of color, graphics, typefaces, and the functionality of special materials, a good set of signage design also needs to fully consider the characteristics of the living 
space and the safe design of the community to make it more

future construction. suitable for modern residents and contribute the community's

TABLE I. INVESTIGATION AND ANALYSIS

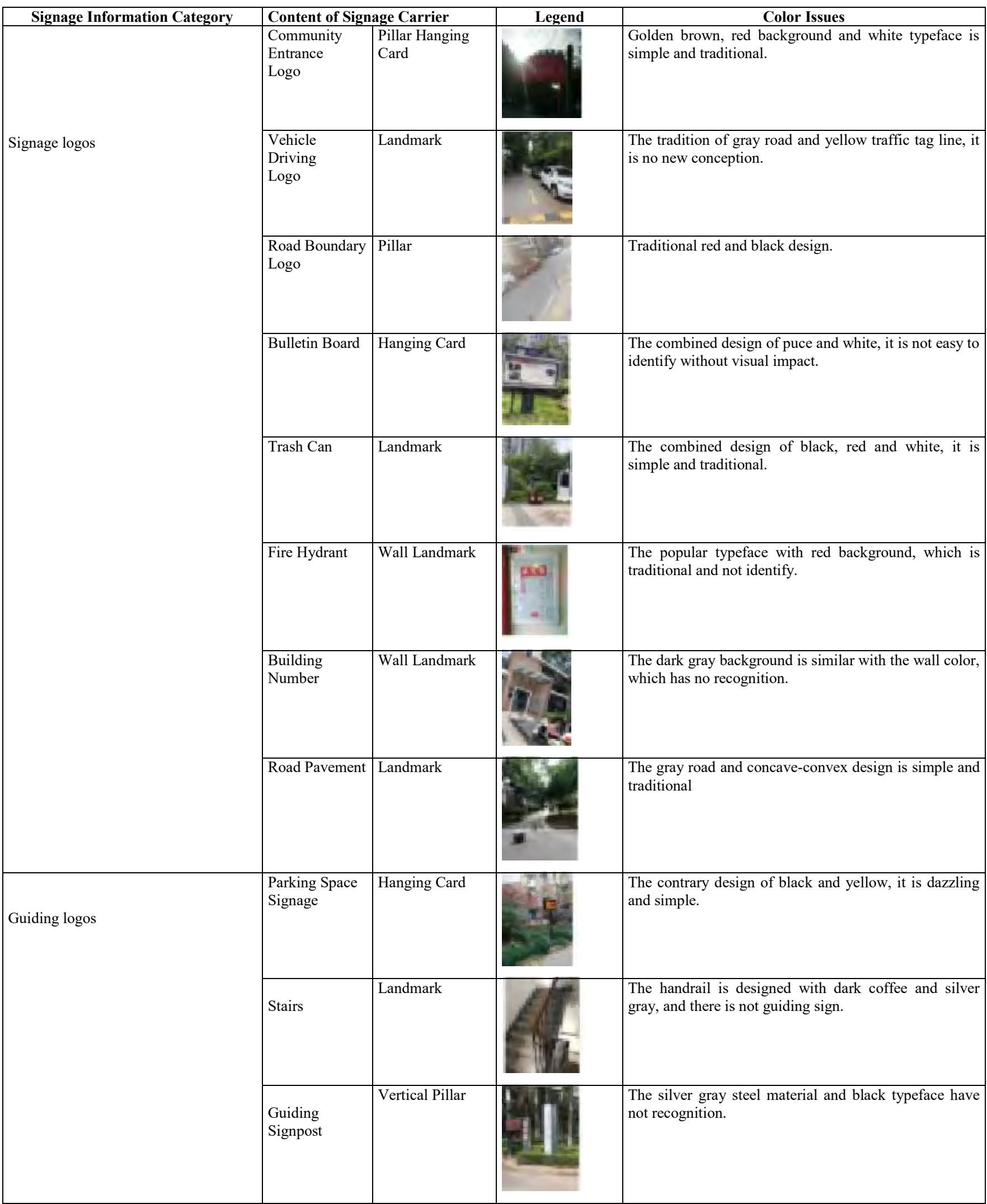


According to the investigation and analysis, Baibuting Community is characterized by relatively simple and popular design style, whose design form is not integrated and uniformed with the environment of the community. The graphic language, color design and modeling design in the signage design lack innovation and recognition. (See "Table I'). Taking Baibuting Community 1 as an example, among the direction signposts, the general information maps, the environmental warning signposts, the evacuation signs, the residential road traffic guidance signs, the bulletin boards, and the trash can (see "Fig. 1") and so on in the signage system, most of the existing facilities in the Baibuting Community use gray or dark coffee color. In addition, the color of the font is too close to the color of the sign to cause no recognition, and

In the visual system for spatial direction guidance, we can use some visually striking colors, which can be quickly noticed, thus having a strong guiding function, and can quickly output and convey correct information to the community residents and managers. According to the investigation in the community, in terms of warning sign color, the elderly prefers yellow, fluorescent green, etc.; men prefer brighter and more striking colors, such as blue; children prefer red, pink and other visually striking colors. ("Fig. 1")

There should be consistency in the visual elements such as graphics, colors, and typefaces in the signage system. The unified and stable signage system is of vital importance for the community residents to quickly find the location and understand the relevant orientation, provides convenience for there is no visual impact. The traffic markings use yellow, which is clear-cut at a glance, but will fade over time, so it needs to be maintained frequently. For traffic guiding signs and fire-fighting logo, their typefaces are too small to be obvious.
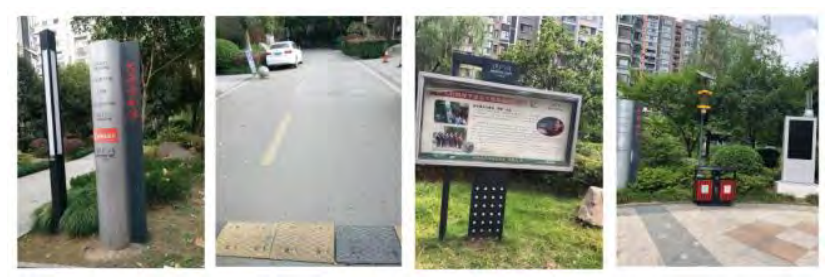

Fig. 1. Signage logos.

residents to get around, as well as improving the management and security functions, so that it can become a visual code of conduct.

\section{Analysis and Design Suggestions of Bailuting Community's Color Current Status}

The author first extracted the signpost color in the existing stage of Baibuting Community, and then analyzed the color according to the CBCC China Architectural Color Card National Standard, and then put forward color suggestions of re-design. The author compared colors from two aspects of $\mathrm{RGB}$ and $\mathrm{LAB}$, and then proposes reasonable practical advice. (See "Fig.2") 


\begin{tabular}{|c|c|c|c|c|c|c|}
\hline \multicolumn{3}{|c|}{ Situation Analysis } & \multicolumn{4}{|c|}{ Innovative Design } \\
\hline Color sample & RGB & LAB & $\begin{array}{l}\text { Color } \quad \text { card } \\
\text { code }\end{array}$ & Color sample & RGB & LAB \\
\hline & $\begin{array}{c}\mathrm{R}=121 \quad \mathrm{G}=121 \\
\mathrm{~B}=121\end{array}$ & $\begin{array}{c}\mathrm{L}=51 \quad \mathrm{~A}=0 \\
\mathrm{~B}=0\end{array}$ & 0472 & & $\begin{array}{c}\mathrm{R}=218 \quad \mathrm{G}=226 \\
\mathrm{~B}=234\end{array}$ & $\begin{array}{c}\mathrm{L}=89 \quad \mathrm{~A}=-2 \\
\mathrm{~B}=-5\end{array}$ \\
\hline & $\begin{array}{c}\mathrm{R}=222 \quad \mathrm{G}=190 \\
\mathrm{~B}=139\end{array}$ & $\begin{array}{c}\mathrm{L}=79 \quad \mathrm{~A}=7 \\
\mathrm{~B}=30\end{array}$ & 0431 & & $\begin{array}{c}\mathrm{R}=231 \quad \mathrm{G}=231 \\
\mathrm{~B}=233\end{array}$ & $\begin{array}{c}\mathrm{L}=92 \quad \mathrm{~A}=0 \\
\mathrm{~B}=-1\end{array}$ \\
\hline & $\begin{array}{c}\mathrm{R}=246 \quad \mathrm{G}=230 \\
\mathrm{~B}=171\end{array}$ & $\begin{array}{c}\mathrm{L}=92 \quad \mathrm{~A}=-1 \\
\mathrm{~B}=31\end{array}$ & 0556 & & $\begin{array}{c}R=103 \quad G=129 \\
B=148\end{array}$ & $\begin{array}{c}L=52 \quad A=-6 \\
B=-13\end{array}$ \\
\hline & $\begin{array}{c}R=28 \quad G=33 \\
B=36\end{array}$ & $\begin{array}{c}\mathrm{L}=12 \quad \mathrm{~A}=-2 \\
\mathrm{~B}=-3\end{array}$ & 0562 & & $\begin{array}{c}\mathrm{R}=206 \quad \mathrm{G}=230 \\
\mathrm{~B}=232\end{array}$ & $\begin{array}{c}\mathrm{L}=90 \quad \mathrm{~A}=-8 \\
\mathrm{~B}=-4\end{array}$ \\
\hline & $\begin{array}{c}R=202 \quad G=206 \\
B=209\end{array}$ & $\begin{array}{c}\mathrm{L}=83 \quad \mathrm{~A}=-1 \\
\mathrm{~B}=-2\end{array}$ & 1163 & & $\begin{array}{c}\mathrm{R}=37 \quad \mathrm{G}=103 \\
\mathrm{~B}=58\end{array}$ & $\begin{array}{c}\mathrm{L}=39 \quad \mathrm{~A}=-30 \\
\mathrm{~B}=19\end{array}$ \\
\hline & $\begin{array}{c}\mathrm{R}=255 \quad \mathrm{G}=128 \\
\mathrm{~B}=135\end{array}$ & $\begin{array}{c}\mathrm{L}=69 \quad \mathrm{~A}=50 \\
\mathrm{~B}=20\end{array}$ & 1674 & & $\begin{array}{c}R=191 \quad G=55 \\
B=61\end{array}$ & $\begin{array}{c}\mathrm{L}=45 \quad \mathrm{~A}=55 \\
\mathrm{~B}=30\end{array}$ \\
\hline & $\begin{array}{c}R=0 \quad G=0 \\
B=0\end{array}$ & $\begin{array}{c}\mathrm{L}=0 \quad \mathrm{~A}=0 \\
\mathrm{~B}=0\end{array}$ & 0856 & & $\begin{array}{c}\mathrm{R}=238 \quad \mathrm{G}=233 \\
\mathrm{~B}=176\end{array}$ & $\begin{array}{c}L=92 \quad A=-5 \\
B=28\end{array}$ \\
\hline & $\begin{array}{c}R=101 \quad G=65 \\
B=43\end{array}$ & $\begin{array}{c}\mathrm{L}=31 \quad \mathrm{~A}=14 \\
\mathrm{~B}=20\end{array}$ & 1112 & & $\begin{array}{c}\mathrm{R}=253 \quad \mathrm{G}=195 \\
\mathrm{~B}=47\end{array}$ & $\begin{array}{c}\mathrm{L}=82 \quad \mathrm{~A}=12 \\
\mathrm{~B}=75\end{array}$ \\
\hline & $\begin{array}{c}\mathrm{R}=163 \quad \mathrm{G}=89 \\
\mathrm{~B}=62\end{array}$ & $\begin{array}{c}\mathrm{L}=47 \quad \mathrm{~A}=36 \\
\mathrm{~B}=35\end{array}$ & 1261 & & $\begin{array}{c}\mathrm{R}=50 \quad \mathrm{G}=50 \\
\mathrm{~B}=52\end{array}$ & $\begin{array}{c}\mathrm{L}=21 \quad \mathrm{~A}=0 \\
\mathrm{~B}=-1\end{array}$ \\
\hline & $\begin{array}{c}R=108 \quad G=107 \\
B=105\end{array}$ & $\begin{array}{c}\mathrm{L}=45 \quad \mathrm{~A}=0 \\
\mathrm{~B}=1\end{array}$ & 1026 & & $\begin{array}{c}R=65 \quad G=66 \\
B=56\end{array}$ & $\begin{array}{c}\mathrm{L}=28 \quad \mathrm{~A}=-2 \\
\mathrm{~B}=6\end{array}$ \\
\hline & $\begin{array}{c}\mathrm{R}=91 \quad \mathrm{G}=76 \\
\mathrm{~B}=37\end{array}$ & $\begin{array}{c}\mathrm{L}=33 \quad \mathrm{~A}=2 \\
\mathrm{~B}=25\end{array}$ & 0541 & & $\begin{array}{c}\mathrm{R}=170 \quad \mathrm{G}=186 \\
\mathrm{~B}=195\end{array}$ & $\begin{array}{c}\mathrm{L}=74 \quad \mathrm{~A}=-4 \\
\mathrm{~B}=-7\end{array}$ \\
\hline & $\begin{array}{c}\mathrm{R}=36 \quad \mathrm{G}=42 \\
\mathrm{~B}=28\end{array}$ & $\begin{array}{c}\mathrm{L}=16 \quad \mathrm{~A}=-5 \\
\mathrm{~B}=8\end{array}$ & 1506 & & $\begin{array}{c}\mathrm{R}=166 \quad \mathrm{G}=148 \\
\mathrm{~B}=145\end{array}$ & $\begin{array}{c}\mathrm{L}=63 \quad \mathrm{~A}=7 \\
\mathrm{~B}=4\end{array}$ \\
\hline & $\begin{array}{c}\mathrm{R}=101 \quad \mathrm{G}=26 \\
\mathrm{~B}=31\end{array}$ & $\begin{array}{c}\mathrm{L}=23 \quad \mathrm{~A}=34 \\
\mathrm{~B}=17\end{array}$ & 0151 & & $\begin{array}{c}\mathrm{R}=209 \quad \mathrm{G}=184 \\
\mathrm{~B}=156\end{array}$ & $\begin{array}{c}\mathrm{L}=76 \quad \mathrm{~A}=6 \\
\mathrm{~B}=18\end{array}$ \\
\hline & $\begin{array}{c}R=149 \quad G=38 \\
B=45\end{array}$ & $\begin{array}{c}\mathrm{L}=34 \quad \mathrm{~A}=47 \\
\mathrm{~B}=25\end{array}$ & 0772 & & $\begin{array}{c}\mathrm{R}=190 \quad \mathrm{G}=207 \\
\mathrm{~B}=172\end{array}$ & $\begin{array}{c}\mathrm{L}=81 \quad \mathrm{~A}=-11 \\
\mathrm{~B}=15\end{array}$ \\
\hline & $\begin{array}{c}\mathrm{R}=173 \quad \mathrm{G}=187 \\
\mathrm{~B}=188\end{array}$ & $\begin{array}{c}\mathrm{L}=75 \quad \mathrm{~A}=-5 \\
\mathrm{~B}=-2\end{array}$ & 1024 & & $\begin{array}{c}R=60 \quad G=66 \\
B=56\end{array}$ & $\begin{array}{c}\mathrm{L}=27 \quad \mathrm{~A}=-4 \\
\mathrm{~B}=5\end{array}$ \\
\hline & $\begin{array}{c}\mathrm{R}=255 \quad \mathrm{G}=240 \\
\mathrm{~B}=76\end{array}$ & $\begin{array}{c}\mathrm{L}=94 \quad \mathrm{~A}=-8 \\
\mathrm{~B}=76\end{array}$ & 1162 & & $\begin{array}{c}\mathrm{R}=109 \quad \mathrm{G}=189 \\
\mathrm{~B}=119\end{array}$ & $\begin{array}{c}\mathrm{L}=70 \quad \mathrm{~A}=-37 \\
\mathrm{~B}=27\end{array}$ \\
\hline
\end{tabular}

Fig. 2. Color analysis and suggestion.

\section{Innovation Design of Baibuting Community Color Signage System}

The design of various signage logos formed in the same environment in the Baibuting Community, that is, the design of the signage node system, is of great significance to residents in the community and the first-time visitors. Baibuting Community remains a demonstration site of national civilized community, which is the only community that has won the first "China Habitat Environment Model Award", and Wuhan city, as an important national historical and cultural city and the birthplace of Chu Cultures, has important historical significance. The Baibuting Community is a district structure built before, so there are many things that can be redesigned.
The single node system formed in the Baibuting Community includes a plurality of signposts such as direction signposts, street lights, road pavements, and route instructions. Because it is a practical study towards the color of the signage system in the community, the innovative design will be carried out according to the signage and guiding information involved in the environment and architectural style of the community in the practice link.

1) Innovative design of building number: At the current stage, the color and form of the building number in the Baibuting Community are relatively conventional, so it requires innovation and re-design of them according to the 
architectural style and environment of the community. If we choose colors with recognizability in the design, which can effectively convey information, in addition to the pattern of expression of graphs and texts, the design will help residents or first-time visitors quickly find the building they want to go. The overall design incorporates the color elements in the historical landscape, plus the color style of the environment, thus giving the audiences different feelings in "Fig. 3".

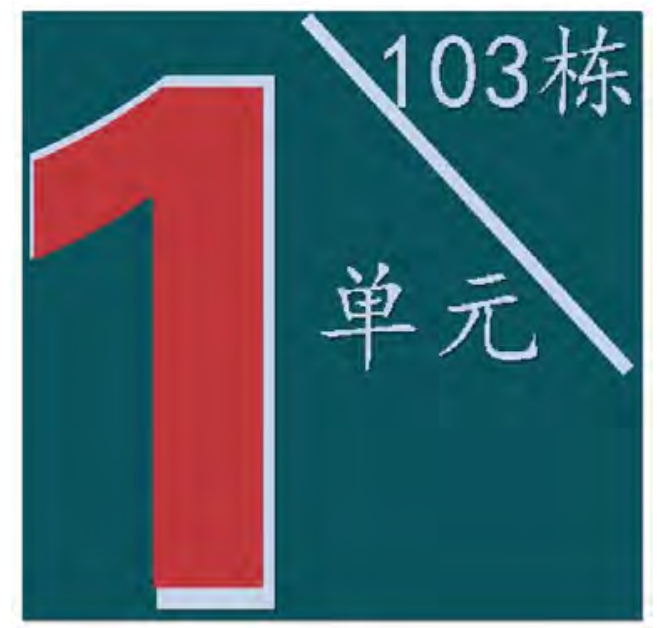

Fig. 3. Building number.

\section{2) Innovative design of road}

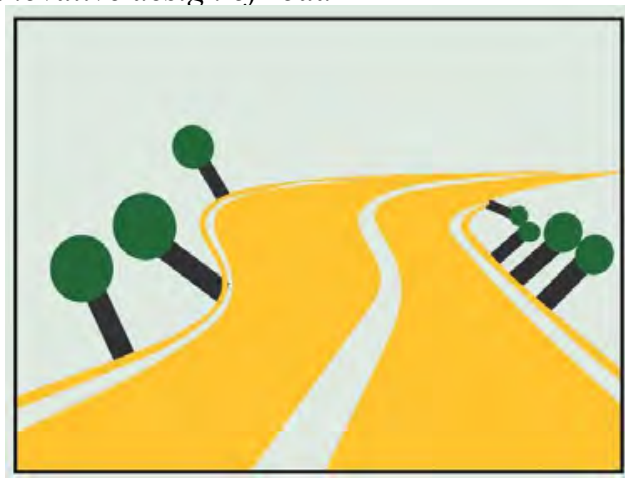

Fig. 4. Road pavement.

The roads in the Baibuting Community adopt the traditional style, which are relatively simple and universal. Therefore, in order to convey the location information to the residents more effectively, and help them quickly grasp the information, we carry out re-innovation and re-design of the color and inject the historical and cultural color elements, and then we conduct the innovation and redesign again. Yellow has a strong distinguishing degree and visual impact, thus capable of reminding people in "Fig. 4".

3) Innovative design of indicative signage: The signpost of Baibuting Community is a simple combination of graphics and texts, characterized by simplex style and lacking differentiation. On this basis, the color elements in the culture and the color forms of the surrounding architectural environment are added to create the design features with the cultural elements, which can attract different people groups and have the clear-cut characteristics. Taking the cultural background as the starting point, the font is Song typeface and the color is white, which is adept for attracting the attention of residents and help them quickly find the desired location in "Fig. 5".
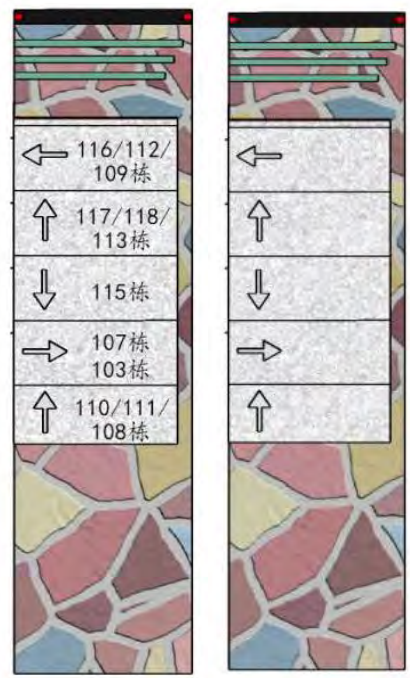

Fig. 5. Direction signpost.

4) Innovative design of street lamps: Baibuting Community adopts solar-powered streetlights that are environmentally-friendly, but without novelty in color and material design, which does not conform to the dock culture of the Baibuting Community. Therefore, in the innovative design, we add historical and cultural backgrounds and use texture materials in addition to architectural colors to make the street lights more designable in "Fig. 6".

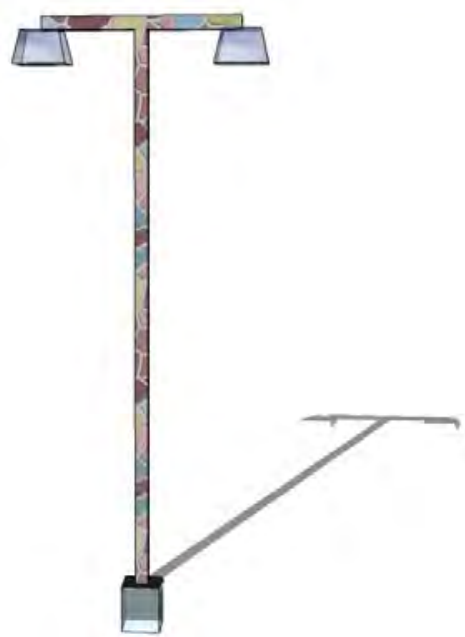

Fig. 6. Streetlight. 
E. Comparison of Color Signage Systems in Baibuting Community and Suggestions Proposed

1) Comparison of color signage systems in Baibuting Community: Results are shown in "Fig.7".

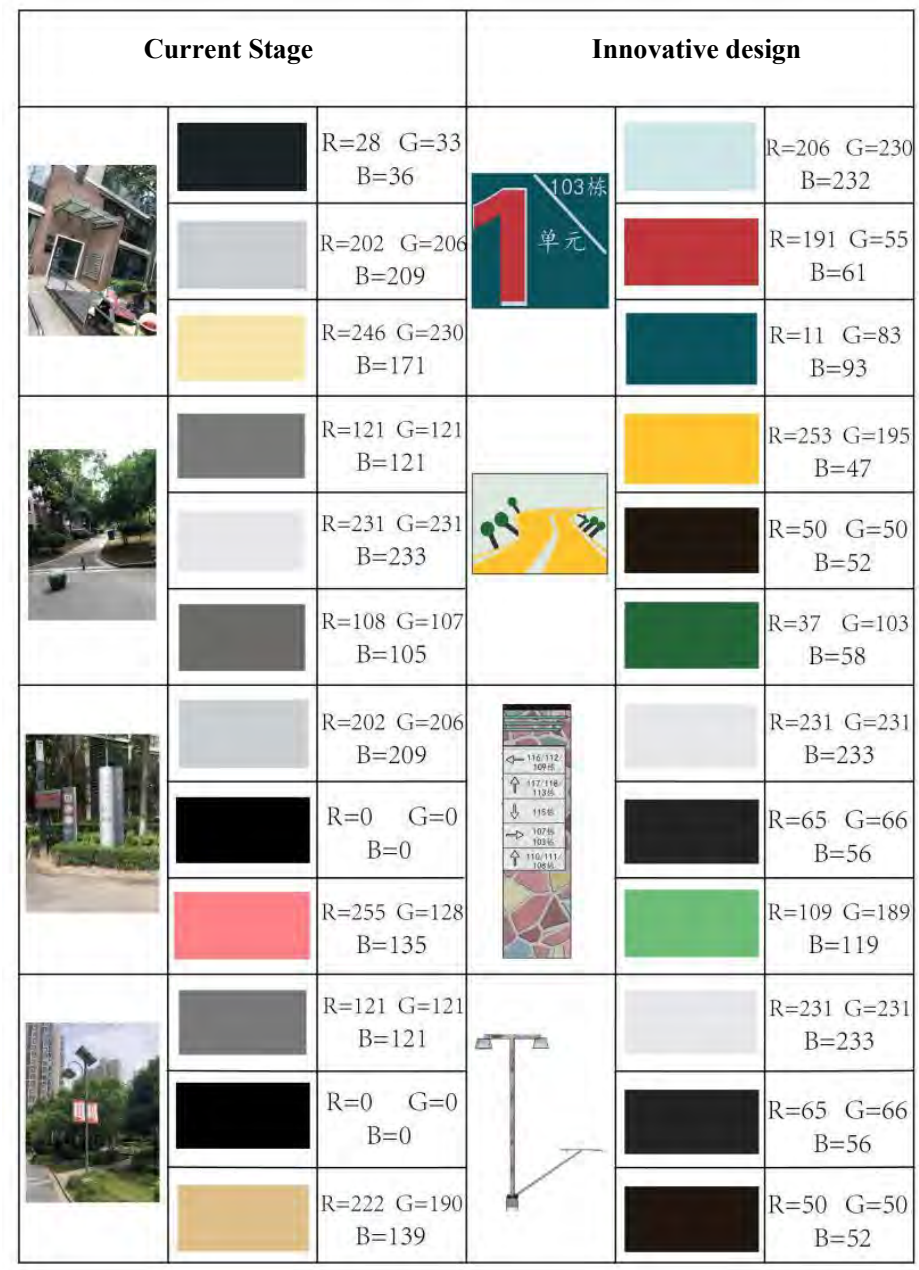

Fig. 7. Comparison of color signage.

2) Baibuting Community color signage system suggestions: At present, the signage design of urban communities in China is in a traditional design mode, which is relatively simple and planar. Therefore, this paper conducts preliminary study of the color in the signage system in the Baibuting Community. At the current stage, the building numbers, road pavement designs, direction signposts and street lights have been innovatively designed, but because the design in the initial stage, further design of the entrance signs, propaganda columns, stair signs, parking signs, fire hydrant, the vehicle road surface and the road boundary logos and a series of signage systems in the Baibuting Community also is needed to finally form a complete set of signage system design.

\section{CONCLUSION}

Signage design is an integral part of modern urban life, with color being especially important. The color-based design philosophy is the essential requirement for the safety of the residential community signage system. In order to establish a complete set of residential community signage system, we should carry out analysis from people's physiology, psychology, thought directions, aesthetic views and relationship with the signage system. In design, we should focus on the color, and adhere to the principle of people first, making it more fit for people's needs.

Through the research of this paper on the embodiment of safe color in the signage system in Baibuting Community and the use of literature review and field research methods, the author analyzes and summarizes the characteristics and patterns of manifestation of the signage system in urban communities. Taking Baibuting Community as an example, 
the author analyzes and practices the color aspects of the signage system and proposes a design scheme. In addition, the color design of the signage system should consider the acceptance factor of the audiences during the dynamic and static propagation process, reflecting its applicability.

First of all, in addition to matching with the life of most people, fabulous design also considers a few of special people groups. It should not only provide valuable things for real life, but also embody the principle of putting people first, with emotions as the main line. Meanwhile, it should make residents of the community recognize this design and meet visual needs. Secondly, it should meet the realistic moral evaluation, and make users can feel the social effects of its education and beautification, feel the moral significance they display, and eventually promote the harmonious life and enjoyment of life. Finally, a good design can reflect the reality in life and make residents understand the meaning in another deep world from the visual effects and experience effects; recognize and respect this design and make another creation on this basis, and see the technologies and the unique modeling abilities in the design.

\section{REFERENCES}

[1] Yan Yan. Central South University. Research on Urban Visual Signage System [D]. 2010,8-17 (in Chinese)

[2] Li Gang. Nanjing University of the Arts. Research on Design of Signage System in Urban Residence Community [D]. 2010, 5-14. (in Chinese)

[3] Yan Yan. Central South University. Research on Urban Visual Signage System [D]. 2010, 8-26. (in Chinese)

[4] Guo Juan. Central Academy of Fine Arts. Analysis on Visual Signage System of Urban Public Space [D]. 2005, 8-42 (in Chinese)

[5] Zhang Wei, Wang Ying. Hubei University of Technology. Research on Signage System Design of Outside Space of Residence for the Elderly - A Case of Baibuting Community, Wuhan City [J]. 2016. (in Chinese)

[6] Donald · Norman. Emotional Design [M]. Publishing House of Electronics Industry. 2005

[7] Andreas - Uebele. Signage System Design [M].China Youth Publishing House. 2014

[8] Hospitable Design for Healthcare and Senior Community. Albert BushBrown, Dianne Davis, Van Nostrand Reinhold. Journal of Women's Health. 2000

[9] Hospital Architecture. Paul Janes and Tony-Noakes. Journal of Women's Health. 2000

[10] Hospital Design and Function. E. Todd Wheeler. Journal of Women s Health. 1964 